Hanson's book is largely effective in identifying key areas of lack in existing scholarship around female gendering in film noir and, particularly, in relation to the female gothic film, and in articulating arguments which demonstrate the importance of considering these fields anew. The limited focus on contemporary articles on the original subject of the gothic film is the book's only major omission. While an understandable result of the author's specific approach, the few brief references included are tantalising enough to encourage the extension of Hanson's project into 1940s criticism and alternative receptions. Ultimately, however, Hanson's work serves well as a valuable addition to Hollywood genre and gender studies.

Karen McNally

doi: $10.1057 /$ fr. 2009.50

\title{
queer French: globalization, language, and sexual citizenship in France
}

Denis M. Provencher; Ashgate, Aldershot, UK, 2007, 236pp., ISBN 978-0-7546-4795-9, £55.00

(hardback)

Queer French engages with a series of questions related to queer citizenship against the specificities of the contemporary French republican (and thus universalising) backdrop. What makes the volume both useful and timely is Provencher's determination to ensure that this republican ideological backdrop be understood within a framework constructed through contemporary trends of globalisation, with a particular focus on their impact on gay popular cultures. Provencher has succeeded in producing a work here that will be of interest not only to scholars and researchers working in French and Francophone studies, but also to those with an interest in gender, gay and lesbian studies, globalisation and transnational cultural movements. In order to frame his own analyses, Provencher focuses on the use of language and the contribution it makes to the evolution of a transnational queer citizenship in contemporary metropolitan France. Language, here, is to be understood as not only encompassing republican discourses and the role played by a small number of canonical voices (Jean Genet and Jean-Paul Sartre, in particular), but also language usage on an individual, everyday basis, as the second part of the volume presents ethnographic data collated through interviews conducted in Paris and Lyon.

The study is clearly divided into two sections. The first sets out the two language traditions at work in the book, namely the language of non-specific difference 
inherent in a traditional French republican model, and the queer language of non-identitarian desire in a tradition Provencher charts back to the writings of Genet. To illustrate these traditions, the author has recourse to a selection of texts drawn from twentieth and twenty-first century French popular culture, from the work of Genet himself to articles and advertisements published in the French monthly gay magazine Têtu. The broad span of cultural texts analysed enables the author, on the one hand, to point towards what he identifies as the beginnings of a shift in 'the collective French gay consciousness' ( $p .38$ ) through the presence, in the pages of Têtu in particular, of a form of 'gay English' that 'reveals signs of a transnational gay culture' ( $p .33$ ). On the other hand, the detailed analysis of the legacy of Genet's figures of the sexual 'outlaw' (Bersani, 1995: 113) or the 'dissident citizen' (Bell and Binnie, 2000: 9, 30) on contemporary French cultural productions, ranging from the fashions of Jean-Paul Gaultier to the photo-collages of Pierre et Gilles, highlights strategies via which alternative, queer citizenships can evolve.

The second section moves from publicly accessible aspects of (popular) culture to ethnographic data collated through interviews conducted with 40 respondents in Paris and Lyon. The interviews centred primarily on questions related to the processes of coming out, which the author sees as particularly relevant to the broader themes dealt with. This allows him to return both to considerations of the use of 'gay English' and to contemporary expressions of models of alternative citizenship inspired by Genet. In the first part of this section, Provencher convincingly argues that the respondents demonstrated an engagement with globalised coming out narratives that situate them within a model of sexual identity framed, broadly speaking, in Anglo-American terms. However, he also points towards a marked tendency on the part of most respondents to place their own 'coming out' in relation to an attempt to establish their own role within the French republican model, underscoring their references to the perceived need to leave behind particular models of dissident sexual citizenship in order to do so. In the second part of the section, Provencher shifts his attention to coming out within the family context, using the latter as a key representation of French republican society insofar as it brings into play questions of filiation and a gendered symbolic order, which have been at the heart of much recent socio-political debate in France.

The second section concludes with a chapter that focuses on a series of maps of gay Paris that Provencher requested his respondents draw during their interviews. The interviewees' responses to this request are, in themselves, revealing, ranging from downright refusal on the grounds that such maps contribute to the establishment of a gay ghetto that, in turn, undermines the universal republican identity, to enthusiastic acceptance of the task and the production of detailed maps of the city. Throughout this second section, although the primary material being analysed is drawn from one-to-one interviews 
conducted by the author, parallels continue to be drawn between these individual experiences and expressions and their place within a wider network of contemporary (popular) cultural relations and productions.

Overall, Provencher's study is thought-provoking, clear, and insightful, entwining the global, the national, and the local in such a way as to maintain accessibility for readers with differing levels of knowledge of the specifics of the contemporary French context. Particularly useful are the brief sections that outline developments in recent scholarship in such areas as sexual citizenship and sociolinguistic analyses of coming out narratives. It is perhaps regrettable that, from the outset, globalisation and its impacts in the French context are equated primarily with the influence of the US. Without wishing to deny the crucial role played by tensions with the US in the development of French gay popular cultures, it would have been interesting to have read more about a truly globalised and globalising network of exchanges. Indeed, the author himself points towards further work to be done in this area in his conclusion that highlights the importance of a transnational dialogue between metropolitan France and the countries of North Africa, in particular. This criticism put to one side, however, Provencher's study offers an important contribution to contemporary considerations of a French republic that is global, transnational, and, crucially, 'always and already queer' (p. 146).

Cristina Johnston

\section{references}

Bell, D. and Binnie, J. (2000) The Sexual Citizen: Queer Politics and Beyond, Malden: Blackwell. Bersani, L. (1995) Homos, Cambridge: Harvard University Press.

doi: $10.1057 /$ fr. 2009.52

\section{queer transitions in contemporary Spanish culture: from Franco to La Movida}

Gema Pérez-Sánchez; State University of New York Press, Albany, New York, 2007, 257pp., ISBN 978-0-7914-7173-9, \$60.00 (hardback)

Queer Transitions in Contemporary Spanish Culture aims to show queer contributions in the negotiation of gender identities and sexual practices from the last years of the Franco dictatorship to the consolidation of democracy. Its specific contribution to the literature that analyses this period's cultural production is to combine an attention to lesbian novelists and artists with gay 